\title{
RAZSEŽNOSTI SNOVANJA DARIJANA BOŽIČA
}

\author{
Andrej Rijavec (Ljubljana)
}

Skladateljska prizadevanja Darijana Božiča so v slovenski glasbeni kuituri svojevrstna, pri čemer se ob ohlapnem in površnem razvrščanju njih značilnosti in dometov vsiljuje presenetljiva protislovnost, in sicer med izborom sredstev, $\mathrm{z}$ drugimi besedami, glasbenega jezika, in vseobsežnimi, pa čeprav v zadnji konsekvenci preprostimi, človeškimi cilji. Če bi zaobrnili latinski rek, bi se lahko dejalo: "Non multum, sed multa", vendar brez poslabševalnih soznačnosti, ampak kot nalepka, kot izhodišče skladateljskih naporov, ki nadrobno ne razčlenjuje zvočnega głradiva v njegovi mikrostrukturi, ampak rabi izdatne količine raznovrstnega, tudi izvenglasbenega, da bi se izpovedalo umetniško hotenje. Potrebe po zvočni in drugačni opremi potemtakem ni jemati vedno kot hibo, ampak kot eno izmed mnogih poti, da bi se doseglo podobno oziroma enkratno. Ker ni možna primerjava različnih rešitev na isto temo, mora izhajati obravnava Božičevega snovanja iz pretehtavanja notranje logike posameznih rešitev. Pokazalo se bo, da pomenijo zastavljene ideje organsko širjenje razmeroma skromnih in neambicioznih glasbenih izhodišč, ki se vedno znova svojstveno uravnovešajo $\mathrm{v}$ zaokroženo in zato zvočno možno celoto.

Božičeve kompozicije so tipičen primer sodobnega skladateljskega opusa, ki ga ne moremo stisniti v pretekle bibliografske okvire: instrumentalne, vokalne in vokalno-instrumentalne kompozicije; ali, opere, kantate, simfonična dela, komorna dela, samospevi, in podobno. Kakor že koli obračamo in etiketiramo posamezne bibliografsske predale, se nekaj ne ujema: ali preostane vrsta stvaritev, ki bi se mogle vtakniti samo pod "razno", ali pa se pride do zaključka, da tradicionalni pojmi ne ustrezajo več, da jih je treba prevrednotiti, jim določiti novo vsebino ter jih dopolniti z novimi. Za potrebe tega sestavka pa se ponuja še ena razdelitev, ki ustreza osnovni dvotirnosti skladateljevega mišljenja in njegovih hotenj, dvotirnost, ki ima za posledico na eni strani komponiranje bolj ali manj "čiste», nepovedne instrumentalne glasbe, na drugi strani pa ustvarjanje, ki razen občasne uporabe sintetičnega zvoka ali/in vizualnega dogajanja, 
vključuje tudi elemente govorjene ali pete besede. ${ }^{1}$ Se pravi: instrumentalno izpoved, ki more biti brez implicitnih izvenglasbenih sestavin, dopolnjuje Božič s takimi skladbami, $\mathbf{s}$ katerimi se ne samo glasbeno izpoveduje, ampak tudi izvenglasbeno pripoveduje. In ravno za to področje se zdi, da je za skladatelja še prav posebno mikavno, ker s svojo idejno in literarno pojmovnostjo bistveno razširja pojmovno nekonkretnost in zato nujno nedorečenost glasbene izpovedi. Še bolj zanimivo pa je dejstvo, da je bistvena glasbena sestavina teh in takih sintez, ki se vlečejo skozi celoten opus, pravzaprav glasbena govorica, ki je sama po sebi in $\mathrm{v}$ okolju, v katerem je nastala, izhodiščno izrazito muzikantska in torej usamozadostnau. $\mathrm{Pa}$ vendar doživlja pri Božiču razširitve in povezave, ki bi se na prvi pogled ponekod lahko zdele navidezno nedopustne, a se že ob tehtnejšem premisleku in analizi pokažejo kot razvojni izrastki podobnih in obenem krčevito humanih in zato umetniško združljivih izhodišč.

Najprej $\mathrm{k}$ instrumentalnemu tiru, in sicer $\mathrm{k}$ skupini tistih kompozicij, $\mathrm{v}$ katerih uspešno povezuje »elemente jazza $\mathrm{z}$ evropsko glasbeno tradicijo«, 2 to je nekatere značilnosti jazza $s$ sodobnimi, serialnimi principi "resne" glasbene umetnosti. Ce izpustimo sočni, a gershwinovsko epigonski Koncert za klavir in orkester (1956), ki je nastajal v času še premajhne obveščenosti o razvojnih težnjah in dospelostih jazza, se kot pars pro toto zdi značilen Concerto grosso (1960), kateremu so sledila dela, kot so na primer Koncert za trombon in orkester (1961), Koncert za trobento in orkester (1961), tri sonate win cool» $(1961,1962,1965)$ itd. Že naslov kømpozicije, Concerto grosso, razkriva eno od bistvenih potez Božičevega snovanja - povezovanja preteklega $\mathrm{z}$ novim, brez apriornega odklanjanja tradicije. Tako ima Concerto grosso solistični concertino in orkestralni tutti, samo da ne gre za kako baročno zasedbo, ampak za pravi »little jazz bandı. že na tej stopnji zahteva ta jazzovska komponenta tolmačenje, ki se zdi simptomatično: imamo opraviti s skladateljem, ki je ob in navkljub tradicionalnemu šolanju stopil $\mathrm{v}$ svet glasbe skozi jazz, skladateljem, ki je že od vsega začetka slišal glasbo skozi jazz in ne morda skozi narodno pesem. Prehitro sklepanje bi seveda vodilo v nepremišljene oznake nekakšne wizkoreninjenosti" in podobnega, če se ne bi pojava obravnavalo kot posledico izrazito urbane sredine, iz katere je skladatelj izšel, sredine, ki še kako odmeva dandanašnji in ki bolj ali manj resnim zvočnim poizkusom mlajših in najmlajših ne odreka pridevka "slovenskosti». To pa pomeni, da sodi Božič v nakazanem smislu med zgodnje, čeprav ne prve primerke take usmerjenosti pri nas. ${ }^{3}$ Če se vstopi $\mathrm{v}$ ta zvočni svet s strani resne glasbe, se zdi, da je to jazz, in obratno. In vendar je zlitje obojega izpovedna možnost, ki so jo drugod po svetu dokazali tudi po Guntherju Schullerju: povezovati serialne principe $\mathrm{v}$ horizontali, vertikali

\footnotetext{
${ }_{1}^{1}$ Rijavec A., Sinteze Darijana Božiča, Zvuk 99/1969, 405 sl.

2. $M E$ 1, 238.

${ }^{3}$ Prim. Rijavec A., $K$ razumijevanju osobina američke popularne glazbe $u$ jugoistočnoj Evropi, Zvuћ 1977/3, 72 sl.
} 
in ritmu z jazzovslimi prijemi v melodični liniji, harmoniji in "beat-u巛.4 Medtem ko je prvi stavek (Largo) še nekoliko zadržan in slavnosten, kakor da bi se skladno $\mathbf{s}$ staro jazzovsko tradicijo izvajalci šele ogrevali, pa nadaljni stavki (Kanon, Fuga, Variacije)) razgibajo fakturo. Zlasti v zadnjem stavku je Božič najmanj vklenjen in da duška soliranju in od jazza podedovani, tukaj fiksirani impulzivni improvizacijskosti. Ta sinkopirajoča vitalnost, ki je jazzu tako lastna, ostane v celoti ali v posameznostih navzoča tudi $\mathrm{v}$ nadaljnjem skladateljevem ustvarjanju.

Seveda je to še vedno začetna stopnja v organiziranju zvoka, ki razmeroma tradicionalne prijeme $\mathrm{v}$ harmoniji in ritmu - neglede na jazzovske zglede - povezuje $\mathrm{z}$ delno dodekafonijo $\mathrm{v}$ horizontali, pa tudi $\mathrm{v}$ vertikali. Ob zgledovanju po takih vzorih in lastnih praktičnih preizkusih pride, kot kaže, Božič do zaključka, da je k novemu usmerjena glasba iz razvojno sicer razumljivih vzrokov $\mathrm{v}$ zadnjih desetletjih zanemarila vprašanje sozvočja: ali ga je na eni strani pritirala do blokov mikrobelega oziroma mikrosivega šuma, ali pa se je sozvočje oblikovalo kot stranski produkt linearno vodenih glasov oziroma, $v$ najboljšem primeru, kot ostanek $\mathrm{v}$ horizontalni seriji neuporabljenih poltonov. Tako nastane, skupaj s praktičnnimi rešitvami, saj je Božič izrazit primer muzika-praktika, tudi teoretična študija "Vertikalne strukture savremene muzike», ${ }^{\mathrm{v}} \mathrm{kateri}$ presenečajo analogije, ki obstoje med lastnostmi tradicionalnih terčnih harmonij in elementi novo nastalih akordskih nizov. Še celo več: pokaže se, da so $\mathrm{v}$ Božičevi zasnovi (kako značilno!) terčno izpeljani nizi strukturno najbolj uporabni, medtem ko kvartni vodijo samo v barvna območja. Kaže, da je skladatelj torej našel tisto, kar je hotel najti, namreč sredstvo za racionalno kontrolo vertikale, pa čeprav le-tej manjkajo tako tradicionalni kadenčni kot hierarhični funkcionalni odnosi hindemithovskega tipa. Pač pa je "kontrolirana svoboda» tolikšna, da je samo korak do povezovanja $\mathrm{z}$ jazzovskim in seveda - s serialnim. Odondod na primer zanimive kompatibilne svoboščine $\mathrm{v}$ obravnavanju vodoravnega dvanajsttonskega niza in vertikale v Petih krokijih za trobento, klavir in kontrabas (1963), III. skica (gl. primer na str. 117). 6

Simfonija (1965), ki tudi sloni na teoretičnih zaključkih "Vertikalnih struktur», ima sicer podnaslove $\mathrm{k}$ posameznim stavkom (I - »Slovo od mladosti», II — win spet pomlad razklada svoja čuda...., III - »koder

${ }^{4}$ Gl. Salzman E., Twentieth-Century Music: An Introduction, Englewood Cliffs, 1967, $174-175$.

5 Zvuk 67/1966, 163-188 in 68/1966, 297-321.

6 Pri harmoniji gre za "gornji septimno-terčni akordni niz na tonu e«, v katerem enega od obeh glavnih tonov, ton fis (drugi je ton dis), $v$ eksponirani solistični legi prihrani kot zaključek improvizacijsko se spletajoče, nedosledne dvanajttonske serije, medtem ko je pred tem isti ton skrit $\mathrm{v}$ ustranski skupini, ki jo zaključitev serije oktavno prenese $v$ še višjo, barvno, diskantno lego. - Opozoriti je tudi na terco (gis) $\mathrm{v}$ levi roki klavirske spremljave, ki $\mathrm{v}$ nasprotju $\mathrm{s}$ postavljenimi teoretičnimi izhodišči, a v skladu $s$ starejšim jazzovskim in ne-jaz zovskim zvokom mehča in tradicionalizira postavljeno harmonijo. 


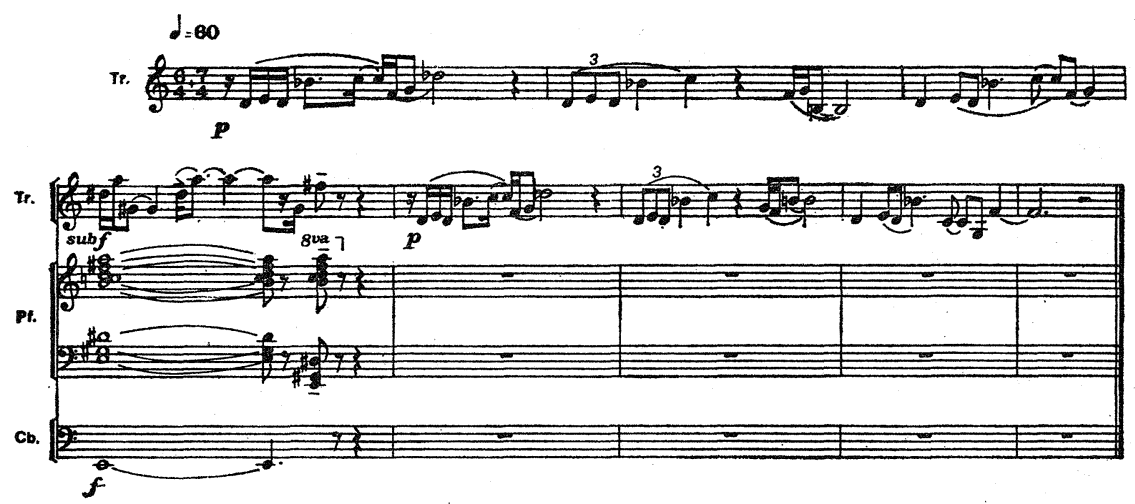

se nebo razpenja grad je pevca brez vratarja....), ki so vzeti iz Prešernovih poezij, vendar pa z njimi (še) nima programskih namenov: nakazujejo samo osnovna vzdušja, ki so ga vodila pri skladanju. Serialnost zopet povezuje $z$ jazzom, a jo na eni strani sprošča $v$ improvizacijah "senza misura», ki so konec koncev tudi jazzovski import, na drugi strani pa jo izmenjuje z zvočnimi gradacijami na podlagi harmonskih nizov, ki dosežejo svoj višek $\mathrm{v}$ šumih in posameznih barvnih blokih. Zopet so jazzovsko oblikovane teme tiste, ki nas po teh zvočnih izbruhih vračajo $\mathrm{v}$ bolj preprosto realnost in nas $\mathrm{v}$ razpotegnjeni melodični liniji prvih violin tretjega stavka opomnijo, da se je skladatelj, kot že mnogokrat, vzoroval tudi pri Georgeu Gershwinu.

Če Simfonija še sledi tradicionalni kontrastni trostavčnosti, uberejo Elongacije za klavir in dvanajst instrumentov (1967) nekoliko drugačno pot, ki obenem pomeni začetek drugačnega načina zastavljanja forme. Gre za izrazitejši prenos vizualnih oblikovnih možnosti in rešitev na glasbeno področje, tako da je že možno govoriti o nekakšni slušni geometriji kot povzetku vizualnih variant. Ta kompozicija ima ime po sinusovi krivulji, ki je osnova njene forme, pri čemer je spodnja polovica krivulje predstavljena tako, da se njen prvotno negativni vrh dotika abscise. Na ta način je skladatelj dobil trden formalni okvir $s$ tremi zvočnimi viški: na sredi prvega stavka (Amplituda I) ter na začetku in koncu drugega (Amplituda II). Partitura potrjuje zvočni vtis, po katerem skladatelj ustrezno naslovu in oblikovalni ideji časovno zgošča oziroma redči zvok, s čimer spreminja izrazno napetost. Opaziti pa je dvojnost v zgoščevanju, saj horizontala in vertikala hodita deloma samostojna pota, da bi se $\mathrm{v}$ občasnih viških združili. Viškom sledijo generalne pavze - tišina, ki samo še stopnjuje efekt. Zaslediti je tako aleatorično improviziranje $\mathrm{v}$ »okvirjihı kot naklonjenost jazzu, za katerega je značilna linearna tematičnost $\mathrm{v}$ razpoznavnih različicah vedno znova prisotna.

Nadaljnja dela izpričujejo nadaljnja skladateljeva iskanja $v$ tem mediju. Polyrhythmia (1968) za pihalni kvintet predstavlja nekakšno, po 
ritmu in tematiki troglasno fugo, z ekspozicijo, strettami in codo. Pozornost pa vzbujajo trije metronomi, ki se v med seboj različni hitrosti gibljejo skozi celotno skladbo in le-to $\mathrm{s}$ svojim značilnim tik-takanjem polifonsko tudi vpeljujejo in zaključujejo. Da je do naslednje kompozicije Pop-art I (1969) blizu, je razumljivo, saj je napisana za pikolo, dve violini, violončelo in za veliki in mali mentronom ter uro (s sekundnim kazalcem!). Vplivi likovne umetnosti, ki so skladatelja na področju povezovanja besede in tona vodili do najrazličnejših collageov, o katerih bo še govor, rezultirajo tukaj ne samo $\mathrm{v}$ principu kontroliranega in improvizacijskega nalaganja zvoka, ampak tudi v vključitvi tujerodnih predmetov, ki pa so po svojem namenu tako ali drugače povezani z glasbeno produkcijo in reprodukcijo. Skladateljevi pop-arti se instrumentalno izcistijo s tretjim, Pop-artom III za godalni kvartet (1971), katerega stavki nosijo naslove neglasbenih form, tukaj, Forma V in Forma VI. Analiza slednjega je pokazala, da je delo podobno zasnovano kot pri tradicionalnem skladanju, ko si skladatelj zamisli svojo bodočo kompozicijo $\mathrm{v}$ njenih osnovnih konturah. "In vendar drugače: ker sedaj ne izhaja iz teme, tipičnega motiva, izhodiščnega sozvočja in podobno, ampak zvočno platno polni s kombinacijami teh, na zvočne 'prafaktorje' reduciranih gradbenih elementov. Rezultat je polifonsko sosledje zdaj bolj statičnih zdaj bolj mobilnih zvočnih barv $\mathrm{v}$ sicer značilnem godalnem zvoku».?

Poslej nastane vrsta audiostrukturnih oziroma audiografičnih geometrij, ki jih najbolje označuje skladateljeva lastna izjava ob prvi izvedbi Audiogema I-IV (1974) na 8. zagrebškem bienalu (1975), namrec: "U poslednje vreme se intenzivno bavim problemom kako novim zvučnim materijalom oblikovati novu glazbenu formu. Postupak koji sam nazvao audio-geometrijom $u$ biti se sastoji $u$ primenjivanju totalne serijalne organizacije na zvukovna područja koja do sada još nisu bila njome obuhvaćena. Evo jedno od najjednostavnijih mogućnosti: dvije grafičke linije koje se susreću prenesene $u$ svet zvukova znače ili smenjivanje njegove gustoće (ili instrumentacije), ili smenjivanje njegove jačine, ili zvučne linije dvaju instrumenata koji se približavaju, ili sve to zajedno. Kombinacije različitih varijanti - organizirane na totalno serijalni način - čine $\mathrm{u}$ formalnom smislu novu zvučnu tvorevinuw. ${ }^{8} \mathrm{~V}$ tej in taki luči je torej gledati ne samo ostale Audiogeme (VI-VII, 1975 in V, 1976) pa Audiografiko I-II (1971), ampak tudi naslovno preprostejše skladbe kot so ABA 72 (1972) ali 2B 72 (1972) in podobno, ter končno Audiostructurae za klavir in orkester (1973) ali Audiospectrum za orkester (1972), pri katerem forma slednjega brez sintetičnih barvnih iluzij sledi "principu analognosti optične in zvočne barvne skale" ter kombinacij, ki iz tega lahko nastanejo. ${ }^{9}$ Se pravi, da imamo zavoljo reševanja forme $\mathrm{v}$ njeni makro-strukturi zopet opraviti s prenosom neglasbenih oblikovnih vzorcev $\mathrm{v}$ zvočni svet

${ }^{7}$ Rijavec A., Novejši slovenski godalni kvartet, MZ IX, Ljubljana 1973, 105 sl..

- Komentar $\mathrm{h}$ koncertu dne 15. 5. 1975.

9 Koncertni list Slovenske filharmonije, 3. 10. 1972. 
glasbe. A to so samo zunanja, pa čeprav značilna pomagala $\mathrm{v}$ usmerjevanju mikro-dogajanja, ki strukturni serialnosti navkljub nemalokrat izdajajo $\mathrm{v}$ začetku tega sestavka nakazane poteze Božičevih muzikalnih parametrov. Tako na primer tudi Audiostructurae $\mathrm{v}$ njih drugem delu:

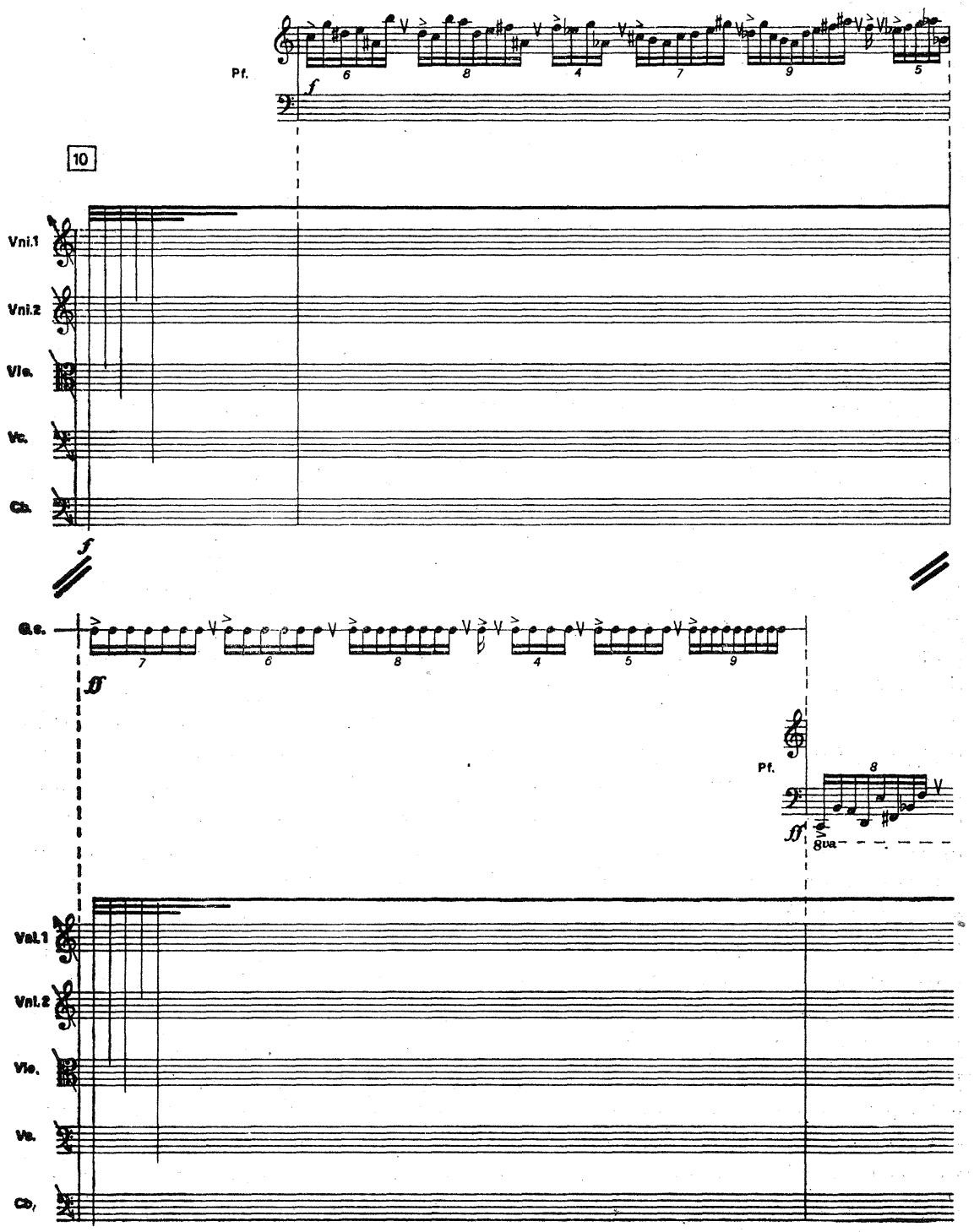

Drugo področje Božičevega ustvarjalnega delovanja, področje, $\mathrm{s}$ katerim razširja tisto, kar neprogramski instrumentalni zvok sam na sebi ne more izraziti, zaobsegajo kompozicije, $v$ katerih se ukvarja $s$ vprašanji povezo- 
vanja besede in zvoka, normalnega, elektronskega in konkretnega. Ta dela značilno osvetljujejo skladateljevo čustveno in miselno orientacijo $\mathrm{v}$ današnjem svetu. Zavoljo uporabe takih ali drugačnih besedil podrobneje definirajo občečloveško stran njegovih hotenj. V njih izstopa in bolj odmeva tekst, tako da predstavlja glasbena stran bolj dopolnilo kot pa jedro umetniške izpovedi. Že po številu in kontinuiteti nastajanja takih del kaže, da je ta, imenujmo jo, dramska glasba, skladatelju zelo pri srcu. Opraviti imamo torej z naravno afiniteto do vrste mejnih področij, na katerih prihaja do simbioze med čisto, tukaj dopolnilno, glasbeno izpovedjo in drugimi mediji izpovedovanja. Zato beleži skladateljev opus aktivnost na področju baleta, opere, scenske in filmske glasbe, kakor tudi izrabo možnosti, ki jih nudi radiofonija, televizija in snemalna tehnika $\mathrm{v}$ mnogoterih svojih različicah.

$\mathrm{V}$ tem okviru so seveda zanimiva tista dela, ki predstavljajo skladateljev napor $\mathrm{k}$ novim, netradicionalnim rešitvam, pa najsi bo to $\mathrm{v}$ smislu siratetične glasbe ali ne. Predvsem pa kaže poudariti, da pri tem ne gre za kakšne visokoleteče, larpurlartistične cilje, ampak za domačijsko uporabne in na "danes in tukaj" naravnane zvočno-miselne sinteze po nezavednem vzorcu ivesovskega "bricolage«, 10 se pravi umne izrabe domačih možnosti, zmožnosti in razsežnosti izpovedovanja.

$\mathrm{Na}$ začetku te razvojne poti, na kateri se lahko sproti zaznavajo sočasne, za instrumentalni stavek značilna oblikovanja zvočne fakture, stojijo "Trije dnevi Anne Frank" (1963) za magnetofonski trak, ki izrablja elektronske in konkretne izvore zvoka, preparirani klavir, nekaj wneprepariranih" instrumentov in recitatorja. Avtor je iz znamenitega teksta mlade judovske deklice vzel tri različna tekstovna vzdušja in jih dopolnil z dvema medigrama - Strahom in Upanjem - ter s pretresljivim Epilogom. Vrsta preteklih in novejših načinov vzbujanja zvoka ustvarja skupaj z ostalimi zvočnimi izvori diferencirano in celo (glasbeno) tematično enotno zvočno kuliso, čez katero je razpeta recitatorjeva pripoved. Če izbor tega teksta kaže na Božičev zavzet odnos do strahot polpretekle dobe, teme, h kateri se bo še povrnil, pa dve nadaljnji kompoziciji - VI. pesem iz Gregorja Strniše cikla "Blaznost» (1965) in Collage sonore (1966) na verze Svetlane Makarovič - razkrivajo posluh za intimno pretresljivi pesniški svet sodobnosti, ki iz pesimizma ("... leži med vrbami, ki so pohabljeni topoli, med majhnimi živalmi s svetlimi očmi ....) najde pot $\mathrm{k}$ svetlobi ("Jutri se bom prebudila $\mathrm{v}$ sonce"). Niti $\mathrm{v}$ eni niti $\mathrm{v}$ drugi ne seže $\mathrm{v}$ insrumentalnem stavku čez kompozicijske prijeme, ki jih uporablja v takratnih uabsolutnih" skladbah. Zato pa v drugi razširi monolog v dia$\log , \mathrm{v}$ konflikt, in s tem spozna nove potencialne možnosti, ki leže v povezovanju starega in novega, različnega in celo nasprotnega. Še isto leto namreč sledi novi collage po drami Antigona Dominika Smoleta, Polineikes, ki je zopet značilna Božičeva amfibija: stoji nekje med radijsko dra-

${ }^{10}$ An Ives Celebration, Urbana 1977, 221. 
mo in koncertnim melodramom ter po svoji zasedbi predvideva kar pet recitatorjev, dva posneta glasova, nepopolna pihala in trobila, štiri zvočnike $\mathrm{k}$ štirim magnetofonom, katerih posnetki (deloma istega, že omenjenega ansambla, deloma "rešetanega» elektronskega zvoka, koralnega petja in vetra) bistveno dopolnjujejo in razširjajo izrazne možnosti. Če prepustimo bibliografu katalogiziranje dela, pa o osnovni ideji skladbe ne more biti nobenega dvoma: ali naj človek živi povprečno življenje in dela celo zlo zavoljo ljubega miru, ali pa naj se dvigne, sledi svoji vesti ter idealom, za katere se je vredno žrtvovati, ker sicer utone $\mathrm{v}$ močvirju sive povprečnosti.

Nemalokrat bi $\mathrm{v}$ teh in naslednjih kompozicijah utegnile motiti prvine jazza, ki so sedaj bolj, sedaj manj očitne. Nikakor pa ni mogoče imeti pomislekov glede takih značilnosti v skladbi Protest Song (1967) na tekst Marta Ogena za glas, klavir in kontrabas ter tri magnetofonske trakove, na katerih je v obliki kontrolirano aleatoričnih mikstur posneto izvajanje trobente, klarineta ter moškega in ženskega glasu tja do jazzovskega sinkopiranega petja na zloge "ta-du-di-ta-di-dap" in podobno, saj je rojstna dežela jazza obenem ena izmed matic zmaterializiranega sveta, proti kateremu to delo protestira: "Ko je vse človeško hrepenenje spremenjeno, strnjeno v željo kupiti si«. V svojem protestu pa gre Božič še dalje v glasbenem happeningu Jagu (1968), ko obsoja vsakršno človeško zatiranje in rasizem.

Tehtnejši v tej seriji «akustičnih gledališč je collage sonore - Requiem (1969) po pesnitvi sovjetskega pesnika Roberta Roždestvenskega. Ce prebiramo komentarje $\mathrm{k}$ pesnitvam tega pesnika, $\mathrm{ki}$ je le leto starejši od Darijana Božiča, ugotovimo, da sta oba, pesnik in skladatelj, morala doživljati vojni in povojni čas na podoben način - wz otroškimi očmi in $z$ otroškim srcemu, se pravi izredno prizadeto, a še ne v vseh odtenkih odraslega človeka, ki more kritično (pravilno?) ocenjevati najrazličnejše obravnave vojne: od rodoljubne, patetične, do intimne, osebne. Prevrednoten odnos do tega vprašanja, ki ga morejo prinesti samo leta, izkušnje in seveda določena mera ustvarjalne svobode, je rodil Roždestvenskega poezijo o vojni. Med najboljše, kar je ustvaril, sodi "Requiem" (1961), ki je v Božiču našel odmevnega nadaljnjega soustvarjalca, ki hoče "ubiti vojno» ín jo celo miselno odpraviti za vse bodoče generacije. Originialni tekst ni uporabljen $\mathrm{v}$ celoti, ampak ga je komponist, deloma razseciranega, razdelil med recitatorje, soliste in zbor in ga $\mathrm{z}$ dodatki iz latinske žalne maše razdelil $\mathrm{v}$ šest miselnih celot oziroma stavkov. Le-ti niti po svojih naslovih niti po svojem značaju ne sledijo gregorjanski predlogi, a tvorijo logično sosledje, pri katerem se lahko najdejo določene vzporednosti s prvotnim obredom. Prvi stavek - Gloria mortis (Slava smrti) - poveličuje smrt herojev. Gloria v pravem requiemu sicer manjka, vendar tukaj, kot nekakšen kyrie, pozdravlja smrt. Decus irae (Lepota jeze), drugi stavek, $\mathrm{s}$ paralelami z Dies irae, vprašuje domovino, ali mora ostati vojak, ki je zanjo padel, zares neznan. Nadaljnji Agon hominis (Krč človeka) 
izraža bolečino matere, ki je izgubila svoje najdražje - sina. Četrti in peti stavek - Benedice (S prijaznimi besedami) in Sanctitas mortuorum (Svetost mrtvih) - zaobračata miselno sosledje in vsebino Sanctusa. Namesto Benedictusa mladi rod neizkušeno in aktivistično $\mathbf{s}$ parolami vzklika prihodnosti, nakar se oglasijo mrtvi in opozarjajo, da se ne sme pozabiti na travo, na drevesa, na reke in oblake, to je na vso lepoto narave, v kateri naj bi človek srečno živel. Tako izzveni zaključni Credar (Težko mi bodo verjeli) $\mathrm{v}$ molitvi (tudi v obliki litanij) proti vojni ter $\mathrm{v}$ novem upanju in zaupanju temu svetu. Partitura sestoji iz "stereofonskih shem", ki določajo zvočno realizacijo že posnetih welementov" - zborovskih, instrumentalnih, solističnih in recitacijskih, ki so zopet močno raznovrstni: homofonija tja do clusterjev, polifonija tja do nediferencirane intonacije in kontrolirane aleatorike, ritmizirano topotanje in ploskanje, glissandi in kriki, stok, šepet, in ne nazadnje različni konkretni zvoki, torej glasben in neglasben zvočni svet $\mathrm{v}$ velikem in malem, predvsem pa pretresljivo zlepljena idejna in muzikalna drama.

Od tu naprej se zdijo vredna pozornosti vsaj tri dela, ki bistveno razširjajo in svojstveno zakorenjujejo Božičeva zvočna prizadevanja: AresEros (1970/72), Slovenske pesmi II (1972) in Bela krizantema (1976). AresEros kot "glasbeno-scenska drama po antičnih motivih" operno sicer ni uspela,11 kar pa je $\mathrm{v}$ sedanji zvezi nebistvenega pomena. $\mathrm{V}$ njej je bolj zanimivo Božičevo glasbeno približevanje tlom, iz katerih je zrasel; se pravi, ob (zanj) starem, jazzovskem, se pojavljajo instrumentacijske, ritmične in intervalne poteze, ki polagoma povezujejo șkladatelja z južṇoslovansko, če že ne takoj slovensko grudo. V slednjem smislu so Slovenske pesmi II, kantata za mezzosopran, recitatorja, napovedovalca in orkester, umetniško priostreni priročnik slovenske nacionalne zavesti in prizadetosti: ne samo da rustikalnost zvočne izpovedi začini $\mathbf{s}$ poltoni istrske barvitosti, $z$ litanijami in zvonovi, $s$ čimer zemljepisno še bolj opredeli dogajanje, ampak seže s collageom tekstov - od slovenskih narodnih, župančiča in Kosovela, Albrehta in Kuntnerja do citatov iz časopisov in originalnih zapisov na smrt obsojenih s sten celic smrti v Begunjah - v srž slovenske preteklosti in sedanjosti, $\mathrm{v}$ bistvu slovenskega narodnega bivanja in nehanja. Vošenje-preludij, Vandrovska, Kmečka, Ples-interludij, Soldaška, Sedmina-postludij so trpke postaje $\mathrm{v}$ usodi malega naroda: janičarstvo, izseljenstvo, talstvo, zdomstvo ... nujno »evakuirajo človešlko dušo«. Bela krizantema, koncertantna drama za igralca-recitatorja, dramatski sopran, bariton in orkester, samo še razširi dimenzije skladateljevih dvomov: mesto in vloga umetnika je skozi Cankarja in ob njem naturalistično stopnjevano pritirana do brezizhodne smrti. Zgodba? (»Kaj bi z njo!») Nikakor ne; pač pa drama takih idejnih in čustvenih razsežnosti, da bi njene katarze vsaj enkrat letno - kot v starih antičnih časih - morali biti deležni vsi, tako "trubadurji domovine» kot ostali. $\mathrm{S}$ tem pa smo

"Rijavec A., Slovenski doprinos zagrebačkom biennalu suvremene glazbe, Arti musices 8/2, Zagreb 1977, 167. 
pri bistvu problema: kako obravnavati te in take Božičeve zvočne stvaritve, ki svojo pripovedno in izpovedno težo dolgujejo predvsem tekstovnemu izboru in njegovi tehtnosti in ne samo, kot ponovno v Beli krizantemi, raznim harmonikarskim in podobnim plesnim vložkom, skratka glasbenemu deležu? Zdi se, da je vrednost Božičevega snovanja prav v tem, da navkljub "urbanim" in "tujerodnim" izhodiščem svojega glasbenega jezika, ki pa je bil zlasti v svojih začetkih jezik "ponižanih in razžaljenih", s svojo pretanjeno glasbeno preobleko pravzaprav aktualizira in obenem stopnjuje idejne razsežnosti posameznih besedil. Njegove lepljenke so zvočno podprte povečave tistih miselnih izmer, ki latentno ležijo na voljo angažiranemu glasbeniku. Po taki poti postaja Božič vznemirljivo slovenski in obenem pretresljivo človeški skladatelj, medtem ko ga vinterdisciplinarnostı pristopov $\mathrm{k}$ zvočnemu gradivu odvezuje ozkih, čisto glasbenih meril obravnavanja, saj jih njegova tovrstna dela $\mathrm{v}$ smislu novega, sodobnega "Gesamtkunstwerka» daleč presegajo.

\section{SUMMARY}

The article deals with the compositional output of Darijan Božič (1933), proceeding from the composer's sthird stream" beginnings and from his theoretical as well as practical solutions as regards the problem of 20th century harmony as one of the most important parametres of serial structure. - His work is devided inito "traditional" compositions, i.e. those dealing with traditional instrumental sound and casts, and into collage compositions in which, apart from the periodic use of synthetic sound or/and visual happenning, he incorporates words spoken or sung. It is in this latter group of works that he achieves a kind of musically supported magnification of many an alarming thought. Here becomes he a deeply moving composer: his winterdisciplinary" approach to the sound material, however, no longer binds him to the narrow, explicitly musical rules of treatment, and this is understandable for works of this kind, in the manner of a new, contemporary "Gesamtkunstwerk", exceed common standards of musical evaluation. 